http://dx.doi.org/10.1590/1678-7366

Arq. Bras. Med. Vet. Zootec., v.67, n.2, p.424-432, 2015

\title{
Morfologia do estômago do cervo-do-pantanal (Blastocerus dichotomus, Illiger 1815)
}

\author{
[Morphology of the marsh deer's stomach (Blastocerus dichotomus, Illiger 1815)] \\ M.R.F. Machado ${ }^{1}$, L.M. Leal ${ }^{1}$ *, T.H.C. Sasahara ${ }^{1}$, F.S. Oliveira ${ }^{1}$, \\ J.M.B Duarte ${ }^{1}$, H. T. Okuda ${ }^{2}$ \\ ${ }^{1}$ Faculdade de Ciências Agrárias e Veterinárias (FCAV-Unesp) - Câmpus de Jaboticabal, SP \\ ${ }^{2}$ Universidade Estadual Paulista (Unesp) - Câmpus de Ilha Solteira, SP

\section{RESUMO}

Em razão da falta de informações sobre a morfologia do cervo-do-pantanal, objetivou-se apresentar a morfologia das câmaras gástricas desse cervídeo. Macroscopicamente, o estômago do cervo-do-pantanal é formado pelo rúmen, retículo, omaso e abomaso, assemelhando-se aos ruminantes domésticos. Microscopicamente, o rúmen e o abomaso são semelhantes aos animais domésticos, já o retículo e o omaso apresentam características específicas, como acentuada queratinização no ápice das pequenas projeções epiteliais do retículo e pregas omasais revestidas por discretas papilas.

Palavras-chave: anatomia, animal silvestre, cervídeo, sistema digestório, ruminante

\begin{abstract}
Based on the lack of information regarding the morphology of marsh deer, this work aims to describe some morphological aspects of the gastric chamber in this species, collaborating with future investigations, mainly related to rational handling in this cervid. This work aimed to describe the morphology of the gastric chamber of the marsh deer, characterizing the external and internal macroscopical details and the microscopical architecture of these structures by light microscopy. Macroscopically, the marsh deer stomach is formed by the rumen, reticulum, omasum and abomasum similar to the domestic ruminants. Microscopically, rumen and abomasum are similar to the domestic ruminants. The reticulum and the omasum, however, present specific characteristics such as keratin on the top of the reticulum, small epithelial projections and omasum folds covered with discrete papillae.
\end{abstract}

Keywords: anatomy, wild animal, cervid, digestory system, ruminant

\section{INTRODUÇÃO}

O Blastocerus dichotomus (Illiger, 1811) pertencente à família Cervidae, é denominado popularmente de cervo-do-pantanal, também conhecido como veado-suaçuapara, guaçupuçu, suaçuate e veado-galheiro. É o maior cervídeo sul-americano, com peso de 100 a $150 \mathrm{~kg}$. Seu pelame é grosso e lanoso, de coloração marromavermelhada; a ponta de sua cauda e a extremidade de seus membros apresentam coloração preta (De Cicco, 2002; Fonseca, 2002).

Recebido em 12 de fevereiro de 2014

Aceito em 2 de abril de 2014

*Autor para correspondência (corresponding author)

E-mail: leonardo.vet@hotmail.com
Segundo Coimbra Filho (1972), esse cervídeo se alimenta de brotos de plantas de diversas famílias, especialmente leguminosas. Hofmann et al. (1976) consideraram para essa espécie alimentação baseada em brotos e folhas, e classificaram esses animais de "browser"ou seletores de concentrados. Schaller (1983) observou o cervo forrageando em Aeschynomene sensitiva (Leguminosae), Discolobium pulchellum (Leguminosae) e Rhabdadenia phollii (Apocynaceae) no pantanal. Tomas e Salis (1996) definiram o Blastocerus dichotomus como um estrategista "pastadorpodador" porque grande parte de sua dieta é composta de brotos de várias espécies arbustivas e macrófitas de folha larga. 
Devido à falta de informações sobre a morfologia desse cervídeo, objetivou-se apresentar a morfologia das câmaras gástricas do cervo-do-pantanal, caracterizar macroscopicamente os detalhes externos e internos, atinentes a esses compartimentos, bem como analisar, à microscopia de luz, a arquitetura dessas estruturas.

\section{MATERIAL E MÉTODOS}

Foram analisados os compartimentos gástricos de 10 animais adultos, que vieram a óbito durante a quarentena, após captura, por ocasião da inundação da área de influência da Usina Hidroelétrica de Porto Primavera, SP, sob licença 013/2001-DIFAC/DIREC. O estudo em questão foi aprovado pela Comissão de Ética no Uso de Animais (CEUA), protocolo número 020115/13, da Faculdade de Ciências Agrárias e Veterinárias de Jaboticabal (FCAV-Unesp), seguindo os critérios do Colégio Brasileiro de Experimentação Animal (COBEA).

Após a morte desses animais, efetuou-se a abertura da cavidade abdominal mediante incisão pré-retroumbilical na linha branca, e, em seguida, a parede abdominal esquerda foi rebatida, para a retirada das vísceras abdominais.

Após a individualização do trato gastrointestinal, procedeu-se à análise e à documentação de sete estômagos a fresco; em sequência, as mesmas peças foram lavadas em água corrente e acondicionadas em recipientes com solução aquosa de formol a $10 \%$ para sua fixação e transporte até o Laboratório de Anatomia do Departamento de Morfologia e Fisiologia Animal da Faculdade de Ciências Agrárias e Veterinárias, Unesp, Campus de Jaboticabal, onde se procedeu à dissecação, análise e documentação desse material.

Para a identificação das características microscópicas, analisaram-se fragmentos das câmaras gástricas dos outros três estômagos, dos quais, logo após o óbito, foram colhidas amostras das regiões dorsal, média e ventral do rúmen; da região média do retículo, do omaso e do abomaso.

Parte dos fragmentos colhidos foi incluída em historesina (Historesin, Leica - Germany). Após a inclusão, obtiveram-se cortes com espessura de
3 a $5 \mu \mathrm{m}$, que foram corados em hematoxilina/eosina e azul de toluidina a $1 \%$. Alguns fragmentos foram incluídos em Paraplast, obtendo-se cortes de $7 \mu \mathrm{m}$. Esses cortes foram corados em hematoxilina/eosina e tricômio de Masson. A documentação foi realizada em microscópio Olympus BX50 com a utilização de filme Fujifilm Fujicolor Asa100 e em lupa Olympus DF Planapo - SZH10.

\section{RESULTADOS}

O estômago do cervo-do-pantanal consiste de quatro compartimentos, rúmen, retículo, omaso e abomaso. O rúmen é a maior das quatro câmaras e apresenta duas faces, duas curvaturas e duas extremidades; esse grande compartimento possui sulcos transversais, mais pronunciados, e longitudinais que o dividem em quatro compartimentos. $\mathrm{O}$ sulco cranial demarca bem o átrio e o recesso do rúmen, e o átrio ruminal se apresenta bastante desenvolvido. O sulco caudal define os sacos caudais, dorsal e ventral; caracteristicamente o saco ventral projeta-se um pouco mais caudalmente do que o saco dorsal. $\mathrm{O}$ sulco caudal continua, na face direita do rúmen, em direção cranial, formando parte do sulco longitudinal direito, pouco acentuado. $\mathrm{O}$ sulco cranial ressalta bem o átrio e o recesso ruminal e continua na parede esquerda do rúmen, delimitando o sulco longitudinal esquerdo, bem como na parede direita, contribuindo para a formação do sulco longitudinal direito que, em parte, tem origem no sulco caudal (Fig. 1). Dos sulcos coronários que delimitam os sacos ruminais cranial e caudal nas direções dorsal e ventral, apenas o sulco coronário dorsal esquerdo mostra-se bem desenvolvido.

Internamente, observa-se que o rúmen é revestido por papilas de forma e distribuição variada. Papilas mais proeminentes são encontradas no átrio ruminal, e à medida que se dirigem caudalmente, essas estruturas vão diminuindo de tamanho, até reduzirem-se a pequenos pontos, pouco proeminentes, na superfície do saco dorsal.

Ainda em posição cranial, várias papilas proeminentes, tais como as do átrio ruminal, ocorrem no recesso do rúmen, e, por toda a extensão do saco ventral, em direção craniocaudal, persiste esse mesmo tipo de papilas. 


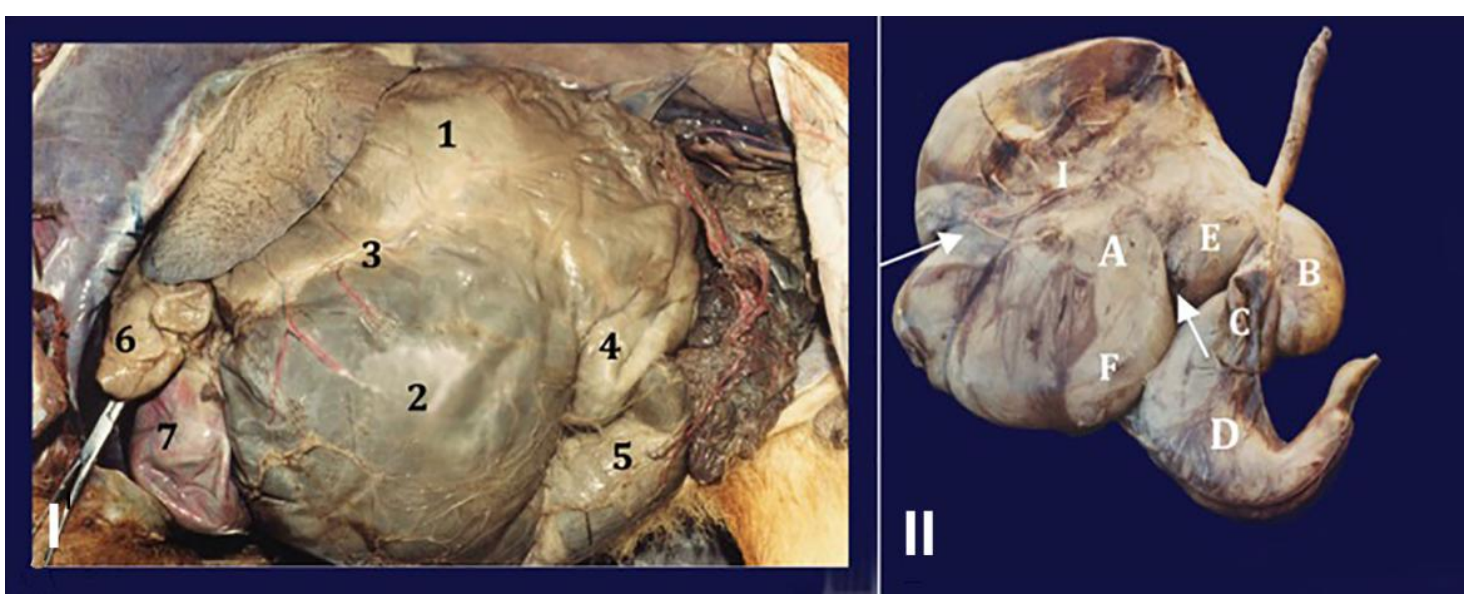

Figura 1. Fotografias das câmaras gástricas de um cervo-do-pantanal adulto. Em I, observam-se esses compartimentos in situ (vista lateral esquerda), evidenciando-se o saco dorsal do rúmen (1); o saco ventral do rúmen (2); o sulco longitudinal esquerdo (3); o saco dorsocaudal (4); o saco ventrocaudal (5); o retículo (6); e o abomaso (7). Em II, observa-se a vista da face direita dessas câmaras, destacando-se o rúmen $(\mathrm{A})$, o retículo $(\mathrm{B})$, o omaso $(\mathrm{C})$ e o abomaso $(\mathrm{D})$ rebatido, os sulcos transversais cranial e caudal (seta), o átrio do rúmen $(\mathrm{E})$, o recesso ruminal $(\mathrm{F})$ e o sulco longitudinal direito (I).

Também internamente, há no rúmen a presença dos espessos pilares cranial, caudal, longitudinal direito, longitudinal esquerdo e coronário, os quais são desprovidos de revestimento papilar e correspondem aos sulcos ruminais. Separando o rúmen do outro compartimento gástrico, o retículo, está a proeminente prega ruminorreticular (Fig. 2).

Em posição cranial ao rúmen está o retículo, uma câmara piriforme e mais desenvolvida que a câmara subsequente, o omaso. Internamente, o retículo apresenta mucosa revestida de estruturas poliédricas variando de quatro a seis lados; a parede dessas estruturas, pouco proeminentes, está revestida de papilas. Também se observa o sulco reticular delimitado pelos espessos lábios reticulares direito e esquerdo. O sulco reticular apresenta demarcações revestidas de escassas papilas; essas estruturas continuam nas folhas omasais (Fig. 2).

O omaso do cervo-do-pantanal é piriforme; está diretamente relacionado, à esquerda, com o rúmen e o retículo e, ventralmente, com o abomaso. Em relação ao retículo, apresenta tamanho reduzido. Internamente, o omaso é revestido por várias pregas delgadas, as lâminas omasais, estruturadas em três ordens de tamanho na seguinte sequência: uma prega bem reduzida, seguida de uma prega maior, de outra também reduzida e outra de tamanho médio; as pregas estão revestidas de papilas (Fig. 3).

Continuamente ao omaso e separado desse por uma prega pouco pronunciada, embora se note a formação de uma rasa saculação, o abomaso, com o formato de um saco alongado, tal qual o estômago unicavitário, situa-se em posição ventral, sob as outras câmaras gástricas.

Internamente, esse compartimento está revestido por pregas mucosas levemente enrugadas, concentradas à região do fundo; a região pilórica apresenta um enrugamento na mucosa; um tórus pilórico arredondado e pouco proeminente é observado no piloro (Fig. 3). 

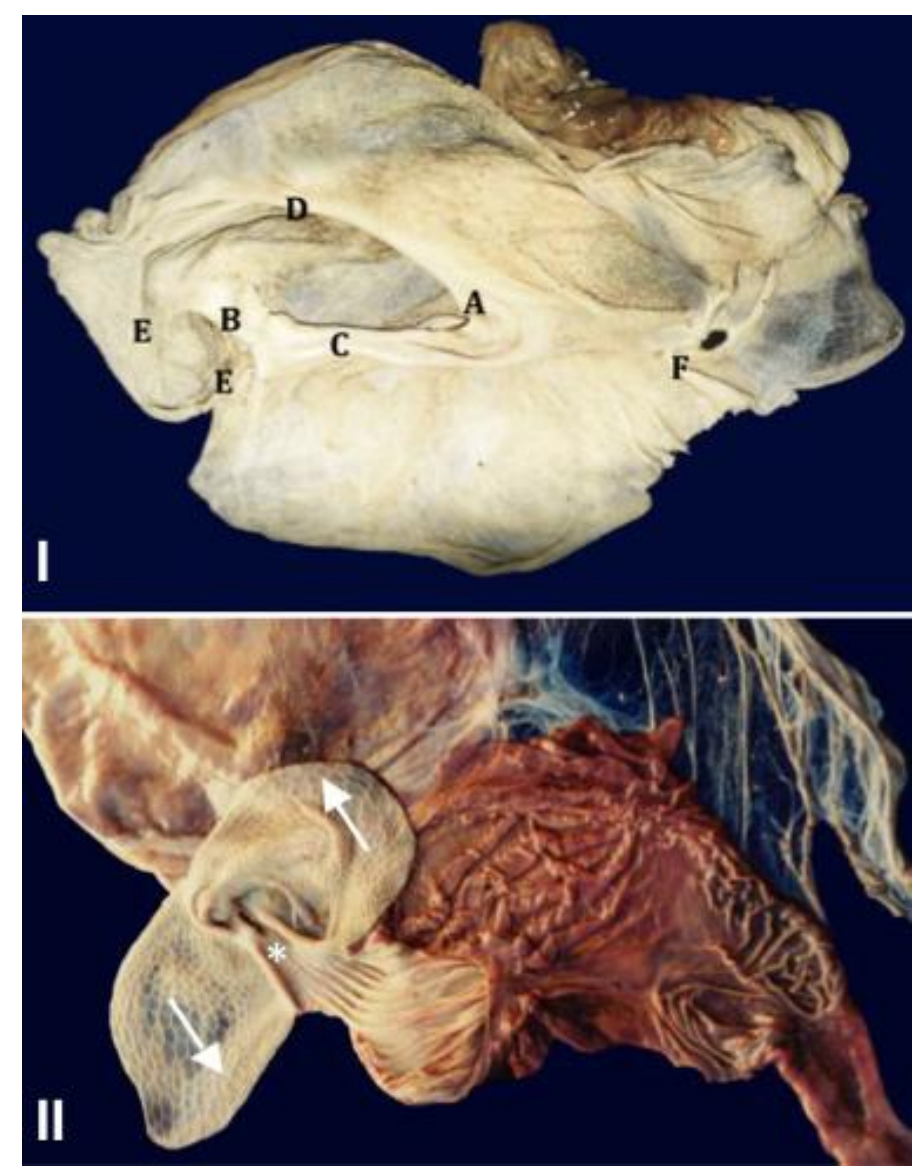

Figura 2. Fotografias da vista interna do rúmen e do retículo de um cervo-do-pantanal adulto (I) e do retículo, do omaso e do abomaso desse cervídeo (II). Em I, observam-se o pilar cranial (A), o pilar caudal (B), o pilar longitudinal direito (C), o pilar longitudinal esquerdo (D), o pilar coronário (E) e a prega ruminorreticular (F). Em II, destacam-se a mucosa reticular, revestida de estruturas poliédricas (seta) e o sulco reticular $(*)$, demarcado por espessos lábios.

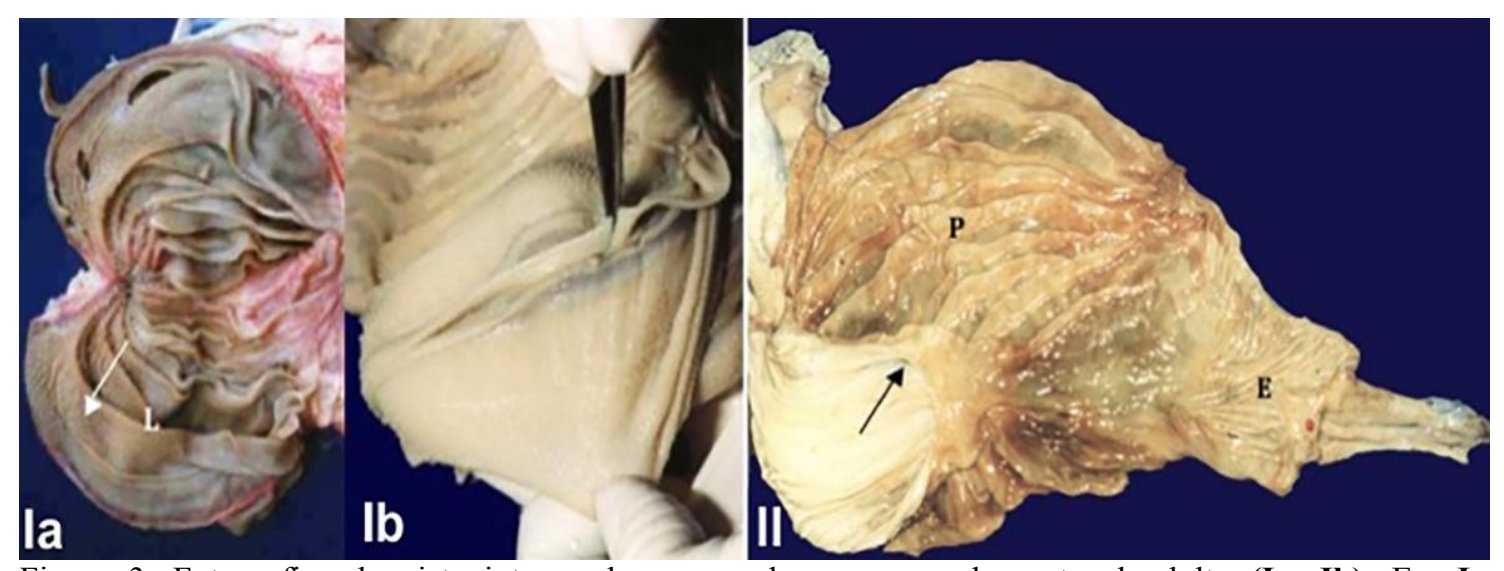

Figura 3. Fotografias da vista interna do omaso de um cervo-do-pantanal adulto (Ia, Ib). Em Ia, observam-se as lâminas omasais (L), recobertas pelas papilas (seta) que revestem essas pregas; em Ib, observa-se a diferença de tamanho dessas pregas. Em II, observa-se a prega omaso abomasal e a formação em fundo de saco (seta), o revestimento por pregas mucosas $(\mathrm{P})$, o enrugamento na região do piloro $(\mathrm{E})$ e o tórus pilórico pouco desenvolvido $(\bullet)$. 
Microscopicamente, o rúmen do cervo-dopantanal se caracteriza por apresentar a mucosa formada de papilas cônicas que se projetam para a luz; essas estão revestidas por epitélio estratificado pavimentoso queratinizado, o qual aparece mais pronunciado nas papilas do saco ventral. As camadas do epitélio são bem definidas, observam-se grânulos de queratohialina no citoplasma de muitas células do estrato granuloso; também se nota que as células poliédricas do estrato espinhoso são maiores que as células do estrato basal; a lâmina própria constitui-se de tecido conjuntivo composto por uma densa rede de fibras colágenas, elásticas e por vasos. Observa-se discreta muscular da mucosa. A submucosa apresenta-se constituída por tecido conjuntivo, composto de fibras colágenas e elásticas frouxamente dispostas, além de grande quantidade de vasos sanguíneos e fibras nervosas, unindo-se à lâmina própria sem qualquer linha evidente de demarcação . A túnica muscular, característica, é formada por duas camadas de músculo liso, uma circular interna e uma longitudinal externa. A túnica serosa é composta de tecido conjuntivo frouxo e vasos sanguíneos e está revestida por mesotélio, epitélio pavimentoso simples (Fig. 4).

O retículo do cervo-do-pantanal apresenta pequenas projeções em sua mucosa, as quais estão revestidas por epitélio estratificado pavimentoso queratinizado; no ápice das projeções, observa-se acentuada queratinização; a submucosa é formada de tecido conjuntivo, composto por fibras colágenas, elásticas e vasos. A muscular da mucosa, formada por músculo liso, está presente, espessando-se nas pontas das pregas reticulares. A camada muscular é característica e é formada por músculo liso. A quarta e última camada, a serosa, é típica e apresenta tecido conjuntivo frouxo e vasos sanguíneos, revestido por mesotélio - epitélio simples pavimentoso (Fig. 4).

O omaso apresenta mucosa formada pelas pregas omasais, revestidas por discretas papilas; o revestimento epitelial é do tipo estratificado pavimentoso queratinizado, com predomínio de queratina no ápice das papilas apoiado em tecido conjuntivo, composto por fibras colágenas, elásticas e vasos que constituem a lâmina própria; a muscular da mucosa é espessa e contínua, formada por músculo liso, e segue o contorno das pregas e das superfícies sem pregas; a submucosa possui a mesma constituição histológica da lâmina própria; a terceira túnica, a muscular, formada por músculo liso, divide-se em subcamadas; a subcamada muscular interna se interdigita com o músculo liso da muscular da mucosa; no interior das pregas no ápice da prega, o músculo liso se funde em uma espessa massa muscular (Fig. 5). A serosa é típica.

A mucosa do abomaso está revestida por epitélio simples prismático mucíparo, que se invagina formando as glândulas ou criptas gástricas, as quais ocupam quase toda a lâmina própria, formada por tecido conjuntivo frouxo; nesse epitélio, identificaram-se dois tipos celulares bem nítidos, as células principais e as células parietais, relacionadas com a produção do suco gástrico; a muscular da mucosa é típica e constituída por músculo liso; a submucosa, característica, está formada por tecido conjuntivo frouxo, ricamente vascularizado; a muscular está formada por músculo liso e é dividida em duas camadas, mostrando-se, ao corte transversal, como circular interna e longitudinal externa; a túnica serosa também é típica, formada por tecido conjuntivo frouxo revestido por mesotélio - epitélio simples pavimentoso (Fig. 5).

\section{DISCUSSÃO}

O estômago do cervo-do-pantanal apresenta a mesma constituição do estômago dos ruminantes domésticos (Schwarze e Schröder, 1970; Frandson, 1979; Nickel et al., 1979; Habel, 1986; Hofmann, 1993; Dyce et al., 2004) do caprino africano (Green e Baker, 1996), do Sambar deer (Stafford, 1995), do Kafue lechwe (Stafford e Staffor, 1991) e do Japanese serow (Yamamoto et al., 1998), entretanto difere do Tragulus javanicus (Agungpriyono et al., 1995), cujo estômago apresenta um rúmen sigmoide formado de saco dorsal, saco ventral e saco cego ventrocaudal; retículo e abomaso.

Também se constatou que o saco ventral caudal do rúmen do cervo-do-pantanal apresentou projeção caudal mais pronunciada, tal qual o rúmen dos pequenos ruminantes (Schwarze e Schröder, 1970; Nickel et al., 1979; Habel, 1986; Dyce et al., 2004), fato não registrado para os cervídeos selvagens, para o caprino africano e para o Japanese serow (Agungpriyono et al., 1995; Green e Baker, 1996; Yamamoto et al., 1998). 

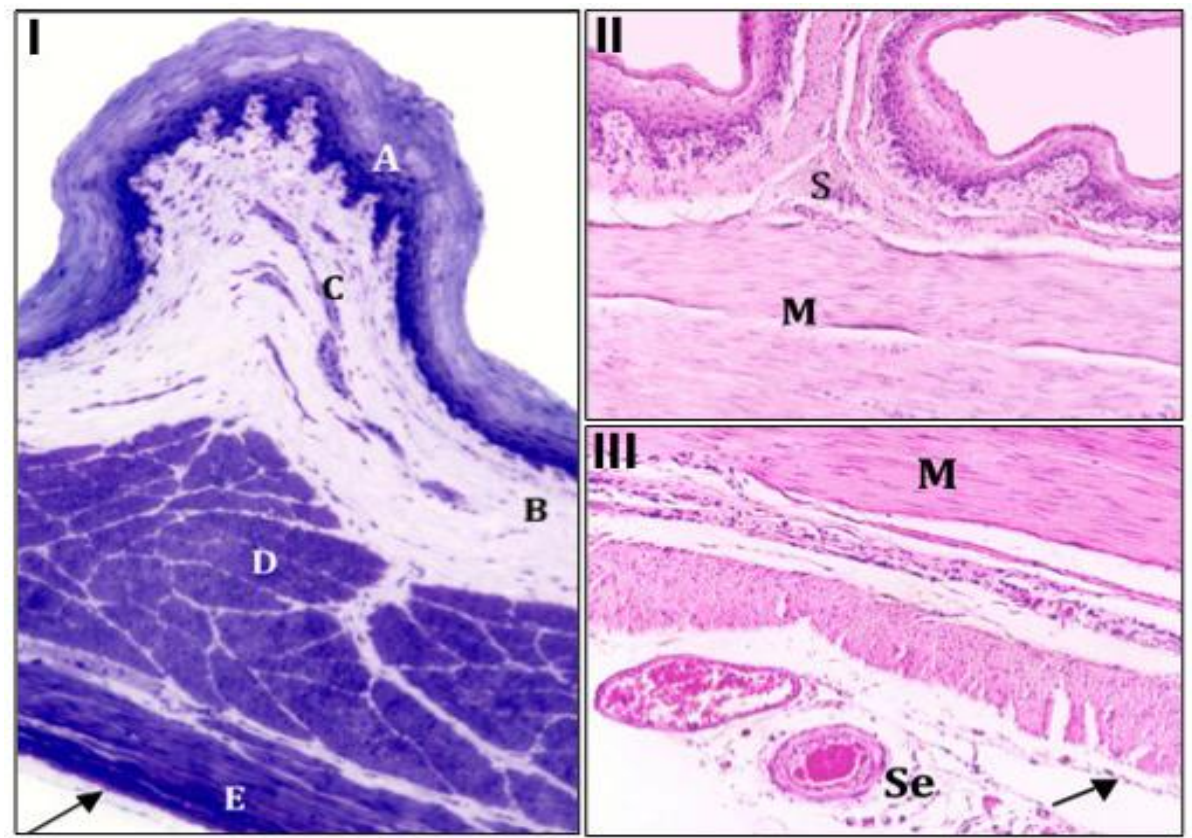

Figura 4. Fotomicrografia da região dorsocaudal do rúmen do cervo-do-pantanal (I): a papila ruminal revestida por epitélio estratificado pavimentoso queratinizado (A); a túnica submucosa (B); uma discreta muscular da mucosa (C); a túnica muscular formada por duas camadas de músculo liso, uma circular interna (D) e uma longitudinal externa (E); túnica serosa (seta) (historesina, azul de toluidina com bórax, aumento 10x). Fotomicrografias do retículo do cervo-do-pantanal (II e III). Em II, observa-se a túnica submucosa, formada de tecido conjuntivo, composto por fibras colágenas, elásticas e vasos sanguíneos (S), além da camada muscular característica, formada por músculo liso (M). Em III, também se observa a camada muscular (M), além da serosa, que apresenta tecido conjuntivo frouxo e vasos sanguíneos (Se), revestido por mesotélio - epitélio simples pavimentoso (seta) (Paraplast, hematoxilina-eosina, aumento 40 vezes em II e 10x em III).

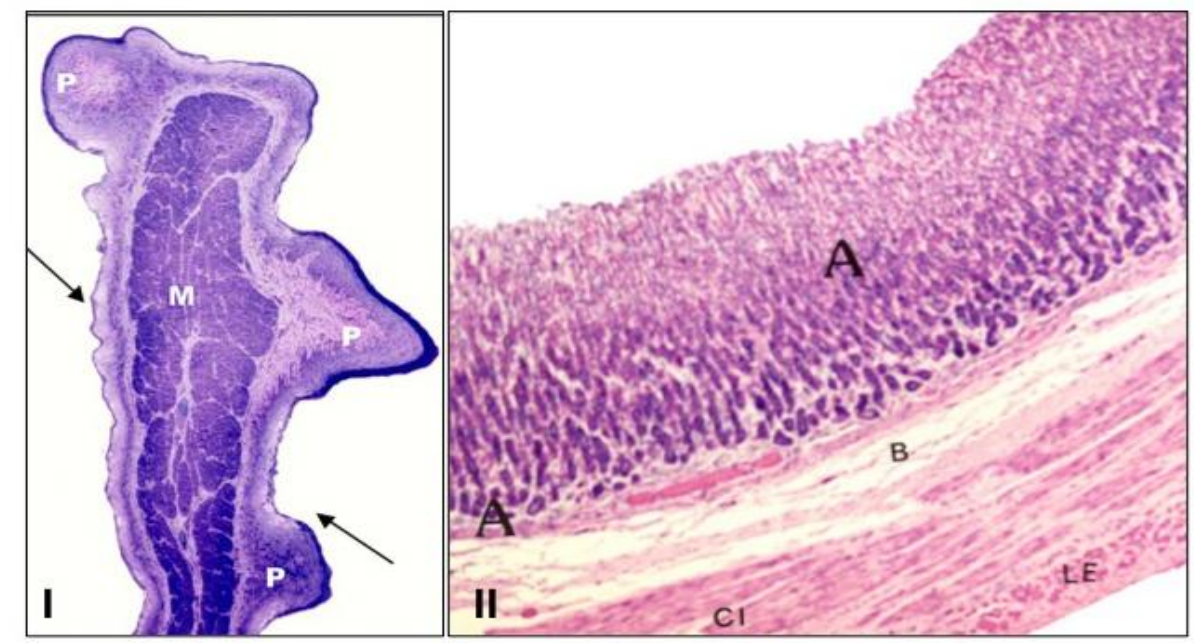

Figura 5. Fotomicrografia do omaso do cervo-do-pantanal mostrando uma prega omasal (I) (entre setas) revestida por discretas papilas $(\mathrm{P})$, com predomínio de queratina em seu ápice; espessa massa muscular no ápice da prega (M) (historesina, azul de toluidina com bórax, aumento 4x). Fotomicrografia da parede do abomaso do cervo-do-pantanal (II): túnica mucosa (A); túnica submucosa (B); camada circular interna da túnica muscular $(\mathrm{CI})$; camada longitudinal externa da túnica muscular (LE) (Paraplast, hematoxilinaeosina, aumento $4 \mathrm{x})$. 
No rúmen do cervo-do-pantanal, os sulcos longitudinais não se apresentam tão demarcados como os dos ruminantes domésticos (Schwarze e Schröder, 1970; Nickel et al., 1979; Habel, 1986; Hofmann, 1993; Dyce et al., 2004), mas nesse cervídeo selvagem os pilares ruminais formam, internamente, projeções bem evidentes, da mesma forma que se observa no rúmen do Kafue lechwe e do Sambar deer (Stafford e Stafford, 1991; Stafford, 1995). Quanto ao sulco coronário dorsal direito, assim como Yamamoto et al. (1998) descreveram para o Japanese serow, também não se observou grande desenvolvimento dessa estrutura. A maior concentração de papilas ruminais no átrio ruminal e no saco ventral verificada no cervo-dopantanal assemelha-se à do Lesser mouse deer (Stafford e Stafford,1991), Sambar deer (Stafford,1995) e Japanese serow (Yamamoto et al.,1998), o que difere da distribuição relatada aos ruminantes domésticos, nos quais as papilas se concentram mais no saco ventral do rúmen.

Semelhantemente ao retículo do bovino e dos pequenos ruminantes (Schwarze e Schröder, 1970; Nickel et al., 1979; Dellmann e Brown, 1982; Habel, 1986; Banks, 1992; Hofmann, 1993; Dyce et al., 2004), esse compartimento gástrico no Lesser mouse deer (Agungpriyono et al., 1992) e no cervo-do-pantanal se apresenta piriforme e revestido por "células" em forma de favo de mel, embora, nesses cervídeos, o retículo seja maior que o omaso, e poucas sejam as cristas secundárias.

O omaso do cervo-do-pantanal apresentou tamanho reduzido, fato também observado nos ovinos e caprinos (Schwarze e Schröder, 1970; Nickel et al., 1979; Habel,1986; Hofmann, 1993; Dyce et al., 2004); já no Sambar deer (Stafford, 1995) e no Japanese serow (Yamamoto et al., 1998), o omaso é oval e bem desenvolvido. De outra forma, Agungpriyono et al. (1992) relatam que o Lesser mouse deer não possui omaso.

Como no cervo-do-pantanal, também no caprino africano (Green e Baker, 1996) foram encontradas várias pregas delgadas omasais de três ordens de tamanho; já no alce (Church e Hines, 1978) e nos animais domésticos (Nickel et al., 1979; Habel, 1986), observaram-se quatro ordens de tamanho para essas pregas. Yamamoto et al. (1998) descreveram, para o Japanese serow, a presença de quatro ordens de lâminas, embora, nestes animais, as lâminas de quarta ordem, ocasionalmente, estejam ausentes. Souza et al. (1990) constataram a presença de cinco ordens de lâminas omasais em bovinos da raça Nelore. Stafford e Stafford (1991) relataram seis ordens de lâminas para o Kafue lechwe. O revestimento papilar das pregas omasais observado no cervo-do-pantanal também foi descrito para o bovino, para o alce, para o caprino africano, para os animais domésticos, para o Kafue lechwe e para o Japanese serow (Brownlee e Eliot, 1960; Church e Hines, 1978; Nickel et al., 1979; Habel, 1986; Souza, et al., 1990; Stafford e Stafford 1991; Green e Baker, 1996; Yamamoto et al., 1998).

O abomaso do cervo-do-pantanal tem forma semelhante ao dos ruminantes domésticos (Schwaze e Schröder, 1970; Nickel et al., 1979; Habel, 1986; Hofmann, 1993; Dyce et al., 2004), do Mithun, do Yak e do bovino zebu (Sarma e Bhattacharya, 1997), embora para esses animais, os pesquisadores utilizem a denominação "piriforme", ao descreverem a morfologia dessa câmara gástrica.

Internamente, o abomaso do cervo-do-pantanal possui pregas mucosas sinuosas e levemente enrugadas, concentradas na região do fundo, tal como relataram Sarma e Bhattacharya (1997) para o Mithun, o Yak e o bovino zebu; Stafford (1995) para o Sambar deer; Stafford e Stafford (1991) para o Kafue lechwe. Sarma e Bhattacharya (1997) acrescentam ainda que, no Mithun, o esfíncter pilórico é espesso, apresentando uma constrição, e que, no Yak e no bovino zebu, esse esfíncter é relativamente mais delgado e com menor constrição. O cervo-dopantanal apresenta, diferentemente desses relatos, tórus pilórico arredondado e pouco proeminente, embora se observe uma constrição nessa região.

A estrutura microscópica do rúmen do cervo-do-pantanal assemelha-se a dos ruminantes domésticos (Dellman e Brown, 1882; Banks, 1992) e também do Lesser mouse deer (Agungpryiono et al., 1992), do Japanese serow (Yamamoto et al., 1998), embora no cervo-dopantanal observe-se a presença de discreta camada muscular da mucosa, diferentemente das afirmações desses autores, que relatam a não existência dessa túnica no rúmen desses animais. Também se observa, nas papilas ruminais do 
cervo-do-pantanal, presença de vários capilares sinusoidais, tal como foi relatado para o Lesser mouse deer (Agungpriyono et al., 1992) e por Hofmann (1993) ao relatar a microestrutura de uma papila ruminal envolvida no processo de absorção.

Quanto aos aspectos microscópicos do retículo do cervo-do-pantanal, destaca-se a acentuada queratinização no ápice das pequenas projeções epiteliais tal como ocorre no Lesser mouse deer (Agungpryiono et al., 1995) e Japanese serow (Yamamoto et al., 1998). As demais características assemelham-se às dos ruminantes domésticos (Dellman e Brown, 1982; Banks, 1992).

Diferentemente do que se observa no omaso dos ruminantes domésticos (Dellman e Brown, 1982; Banks, 1992), histologicamente as pregas omasais do cervo-do-pantanal estão revestidas por discretas papilas. Também não se constataram formas variadas para essas papilas, como relatam Yamamoto et al.(1994) para os ruminantes domésticos.

A constituição histológica do abomaso é típica, semelhante à descrita para os ruminantes domésticos (Dellmam e Brown 1982; Banks, 1992). Na análise da túnica submucosa desse órgão, ao se comparar a quantidade de células parietais e de células principais existentes nessa região, constata-se a presença de maior número de células principais, estruturas produtoras de enzimas, característica essa que, segundo Dellmann e Brown (1982), é uma particularidade dos estômagos unicavitários e, conforme Hofmann (1993), é própria dos ruminantes seletores de concentrados.

A sequência característica das câmaras gástricas do cervo-do-pantanal, como: maior dimensão da câmara reticular quando comparada com a omasal, pouca profundidade das cristas reticulares com rara subdivisão e a presença de pregas abomasais sinuosas e baixas, permite classificá-lo como ruminante "browser" ou seletor de concentrados. Porém, a presença de maior concentração de papilas no saco ventral do rúmen e sua ausência nos pilares ruminais, a presença do epitélio da mucosa ruminal bem desenvolvido e a presença de maior quantidade de células principais na mucosa abomasal possibilitam considerá-lo um ruminante consumidor de gramíneas, verificando que essa peculiar morfologia digestória indica uma especial adaptabilidade apresentada por esse cervídeo.

\section{CONCLUSÃO}

Com exceção de algumas características específicas observadas à microscopia de luz, principalmente relacionadas ao retículo e ao omaso, conclui-se que o estômago do cervo-dopantanal assemelha-se ao dos ruminantes domésticos e ao de alguns selvagens.

\section{REFERÊNCIAS}

AGUNGPRIYONO, S.; YAMAMOTO, Y.; KITAMURA, N. et al. Morphological study on the stomach of the lesser mouse deer (Tragulus javanicus) with special reference to the internal surface. J. Vet. Med. Sci., v.54, p.1063-1069, 1992.

AGUNGPRIYONO, S.; YAMADA, J.; KITAMURA, N. Light microscopic studies of the stomach of the lesser mouse deer (Tragulus javanicus). Eur. J. Morphol., v.33, p.59-70, 1995.

BANKS, W.J. Histologia Veterinária Aplicada. 5.ed. São Paulo: Editora Manole. 1992, p.629.

BROWNLEE, A.; ELLIOT, J. Studies on the normal and abnormal structure and function of the omasum of domestic cattle. Br. Vet. J., v.116, p.467-473, 1960.

CHURCH, D.C.; HINES, W.H. Ruminoreticular characteristics of elk. J. Wild. Manage., v.42, p.654-659, 1978.

COIMBRA FILHO, A. Espécies da Fauna Brasileira ameaçada de Extinção. Rio de Janeiro: Academia Brasileira de Ciências, 1972. p.88-91.

DE CICCO, L.H.S. Cervo-do-Pantanal. Disponível em: <http://www.saudeanimal.com.br/cervo-dopantanal.htm> Acessado em: 13 dez. 2002.

DELLMANN, H.D.; BROWN, E.M. Histologia Veterinária. Rio de Janeiro: Guanabara Kogan ,1982. p.397.

DYCE, K.M.; SACK, W.O.; WENSING, C.J.G. Tratado de Anatomia Veterinária. 3.ed. Rio de Janeiro: Elsevier, 2004. 813p. 
FONSECA, C. Suplemento Estado. Cuidar do Meio ambiente é Preservar a qualidade de Vida. Disponível em <http://www.coelhodafonseca. com.br/SuplementoEstado/SuplementoMateria.as p> Acessado em: 13 dez. 2002.

FRANDSON, R.D. Anatomia e Fisiologia dos Animais Domésticos. 2.ed. Rio de Janeiro: Guanabara Koogan, 1979. 429p.

GREEN, E.D.R.; BAKER, C. The surface morphology of the omasum of the African goat. J.S. Afr. Vet. Assoc., v.67, p.117-122, 1996.

HABEL, R.E. Sistema digestivo dos ruminantes. In: GETTY, R. Anatomia dos Animais Domésticos. 5.ed. Rio de Janeiro: Guanabara Koogan, 1986. v.1, p.807-847.

HOFMANN, R.R. Anatomia Del conduto gastro-intestinal. In: CHURCH, D.C. El Rumiante: Fisiologia Digestiva y Nutrición. Zaragoza:Editorial Acribia, 1993. p.15-46.

HOFMANN, R.R.; PONCE DEL PRADO, C.F.; OTTE, K.C. Registrato de dos nuevas especies de mamíferos para el Peru, Odocoileus dichotomus (Illiger,1811) y Chrysocyon brachyurus (Illiger, 1811) com notas osbre su habitat. Revista Florestal Del Peru., v.5, p.61-68, 1976.

NICKEL, R.; SCHUMMER, A.; SEIFERLE, E. The Viscera of the Domestic Mammals. 2.ed. Berlim:Hamburg Parey, 1979. 401p.

SARMA, K.; BHATTACHARYA, M. Compartive Gross Anatomy of abomasum of mithun (Bos frontalis), yak (Bos grunniensis)and zebu (Bos indicus). Indian J. Anim. Sci., v.67, p.876-877, 1997.
SCHWARZE, E.; SCHRÖDER, L. Compendio de anatomia Veterinária. Zaragoza:Acribia, 1970. p.69-74.

SCHALLER, G.B. Mammals of Uruguay in Brazilian ranch. Arq. de Zool. do Estado de são Paulo, v.3, p.1-36, 1983.

SOUZA,W.M.; SOUZA, N.T.M.; PRADA, I.L.S. et al. Estudo anatômico da Laminas do Omaso em bovinos da raça Nelore. Braz. J. Vet. Res. Anim. Sci., v.27, p.17-23, 1990.

STAFFORD, K.J. The Stomach of the sambar deer (Cervus unicolor unicolor). Anat. Histol. Embryo., v.24, p.241-249, 1995.

STAFFORD, K.J.; STAFFORD, Y.M. The Stomach of the Kafue lechwe (Kobus lechwe kafuensis). Anat. Histol. Embryol., v.20, p.299310, 1991.

TOMAS, W.M.; SALIS, S.M. Composição da dieta do cervo-do-pantanal (Blatocerus dichotomus) na região do Rio Negro, Pantanal Sul Matogrossense. In: SIMPÓSIO SOBRE RECURSOS NATURAIS E SÓCIO-ECONOMICO DO PANTANAL, MANEJO E CONSERVAÇÃO. 2., 1996. Anais... Corumbá, 1996. p.119-120.

YAMAMOTO, Y.; ATIJI, Y.; AGUNGPRIYONO, S; SUZUKI, Y. Morphological study of the forestomach of the japanese serow (Capricornis crispus). Anat. Histol. Embryol., v.27, p.73-81, 1998.

YAMAMOTO, Y.; KITAMURA, N.; YAMADA, J. et al. Morphological study of the surface struture of the omasal laminae in cattle, sheep and goat. Anat. Histol. Embryol. v.23, p.166-76, 1994. 